\title{
2019 SSO Presidential Address: Serendipity and Strategy on the Path of Progress
}

\author{
Armando E. Giuliano, MD ${ }^{1}$ \\ Department of Surgery, Cedars-Sinai Medical Center, Los Angeles, CA
}

It has been an honor to serve as the President of this esteemed Society in what has been a transformational year. The Society of Surgical Oncology has given me decades of great joy, education, and friendship. I have so many people to thank for this great honor-people who helped shape my education, people who shaped my career, and those who helped me function as your president.

I and the Society have benefitted greatly from our recent past presidents. These are all tremendous presidential leaders who taught me a great deal and with whom it was a pleasure to work.

Over the past 2 years, I've spent at least an hour a week on the phone with David Bartlett or Kelly McMasters or, at times, both. I appreciate their friendship, and we all greatly benefitted from their leadership. In addition, our Executive Council has worked hard and were a wonderful group with whom to work. They have served the organization well.

I must thank the surgical oncology faculty and laboratories at Cedars who support me and cover for me when I am gone. They have done a great deal to help me get through the past several years. Vicky Norton and Fernando Esparza run my academic office and keep me functioning. They have each been with me over 15 years and I could not get my work done without them.

I have been fortunate to have been involved in the training of many fellows and residents during my career. I often tortured them and then reminded them they should thank me for the torture. Now I must confess how much they have meant to me and publicly thank them, both

(C) Society of Surgical Oncology 2019

First Received: 10 September 2019; Published Online: 11 October 2019

A. E. Giuliano, MD

e-mail: armando.giuliano@cshs.org complex general surgical oncology and breast oncology fellows whom I have had the pleasure to mentor. I thank them for making my job far more enjoyable and for teaching me probably more than I have taught them. They have all become skilled surgeons. Many of them have gone on to very distinguished careers, and I am fond and proud of every one of them.

When you get to know the staff at the SSO, you realize why the organization works so well. I'd like to commend and thank each and every one of them, especially the Karens-Karen Hurley, Karen Araujo-and Patty, Ana, Becky, Jeanette and, of course, Eileen and the entire staff who work so hard and do so much for all of us. They are wonderful people. They do outstanding work for the SSO.

The family of every surgeon pays a price. Surgeon Mom or Dad's absence is always felt. My work has not always been easy for my family. My son Chris has said that my patients get the best of me; the family gets the rest of me (Fig. 1). What busy surgeon's family has not at times felt that way? I seemed to have missed the work-life balance lecture.

My wife Cheryl has been tremendously supportive and loving since I met her in seventh grade. Without her, my career would not have been possible. In fact, without her, I may not have even gotten into medical school since it was she who typed my applications and helped with the essays. The essays were very well written. Cheryl's Ph.D. from the University of Chicago is in English and she was Director of the Writing program at UCLA for many years.

Thanks entirely to their mother, my twins-Chris and Amanda (Fig. 2) - have become two wonderful young adults. I am very proud of them and am grateful for their love and support. Chris has been producing music and you can hear him on Spotify. He will get his MBA next month. Amanda is working now and plans to start graduate school next fall at NYU. She, too, loves music and sings with the 


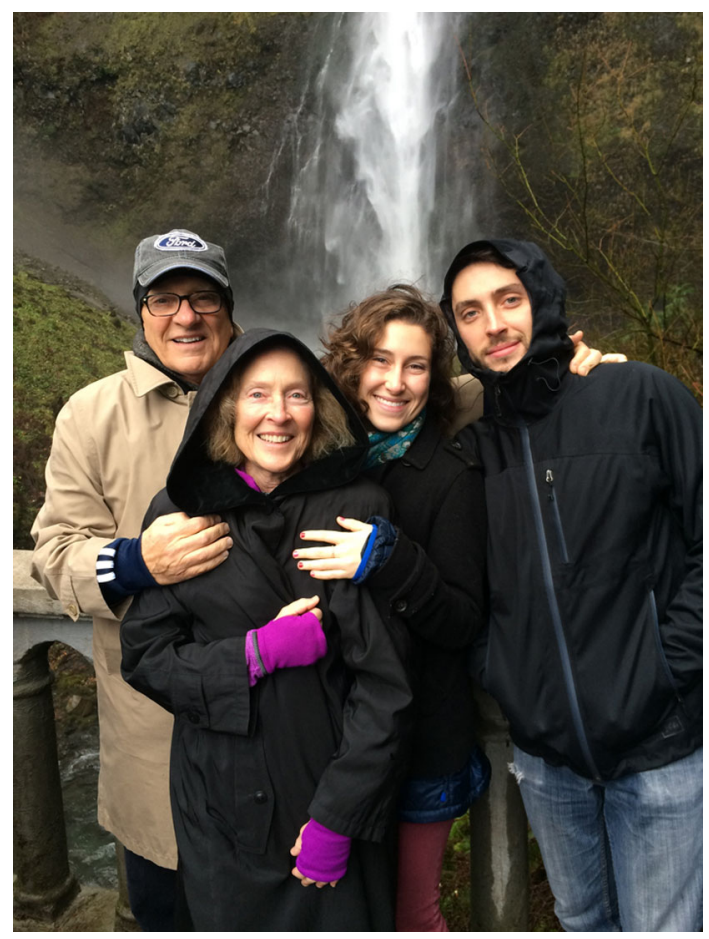

FIG. 1 Armando, Cheryl, Amanda, and Christopher Giuliano

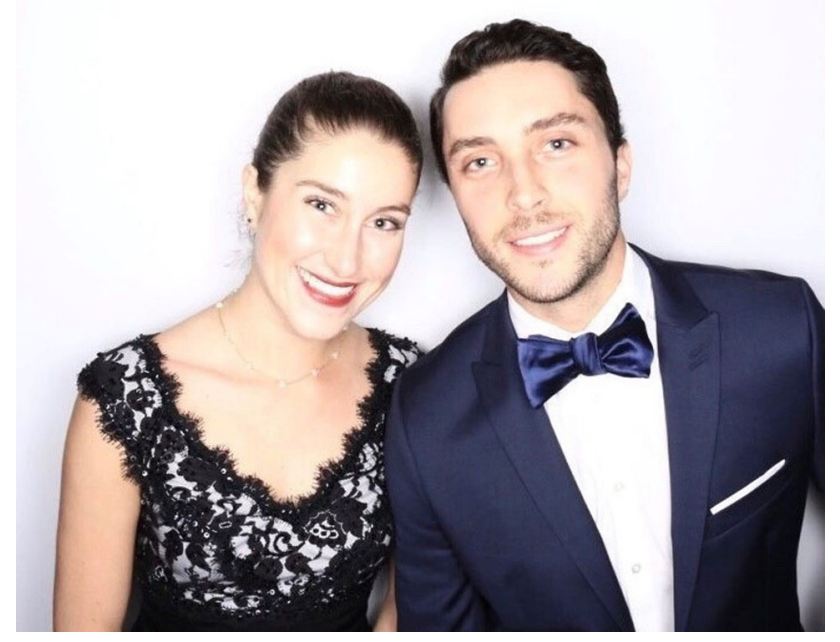

FIG. 2 Amanda and Christopher Giuliano

LOLAS, a group formed when she was a student at USC. No, I did not bribe anyone to get her into USC. The only crime I saw there was the tuition bill they sent to me.

Preparing this address has led to much reflection. Looking at my family, the list of previous presidents and the talented people with whom I have worked, I realize how fortunate I am. My good fortune has been the result of good luck mixed with hard work, strategic planning, and plenty of serendipity. In case you are curious, the word "serendipity" is relatively new in the English language. In
1754, Robert Walpole, the son of Britain's First Prime Minister, created the word based on a Persian fairytale, "The Three Princes of Serendip." Serendip was the Persian name for Sri Lanka. The three princes in the story would strategize and plan a journey in quest of treasure. The journey was always diverted. But the diversion would result in finding an even greater treasure than they initially sought. Serendipity does not mean "luck" as we often think. It means planning for one thing and then finding another, something even better.

The start of my career was in fact serendipitous. When I was a fourth-year medical student at the University of Chicago, I planned to be a cardiologist. My wife Cheryl was a Ph.D. student. I lacked funds to travel to visit residency programs. Fortunately the Department of Surgery was paying fourth-year students to be acting interns. I was assigned to George Block's service (Fig. 3). His service was known to be physically and emotionally demandingemotionally demanding because George was gruff and at times unkind to residents and students. I had no interest in surgery as a career and dreaded the rotation. On service I saw an extraordinary surgeon doing extraordinary work, treating patients with great skill and compassion. This was not the stereotype of surgeons that I had come to believe. The rotation with George Block inspired me to become a surgeon, and I applied in surgery instead of medicine.

Serendipity led to the start of my education in surgery. George and I stayed close for many years until he died quite young. One of the saddest honors of my career was delivering his eulogy at Murphy Hall of the American College of Surgeons.

As an intern at the University of California-San Francisco, I met F. William Blaisdell, Professor of Surgery at UCSF and Chief at the San Francisco General Hospital

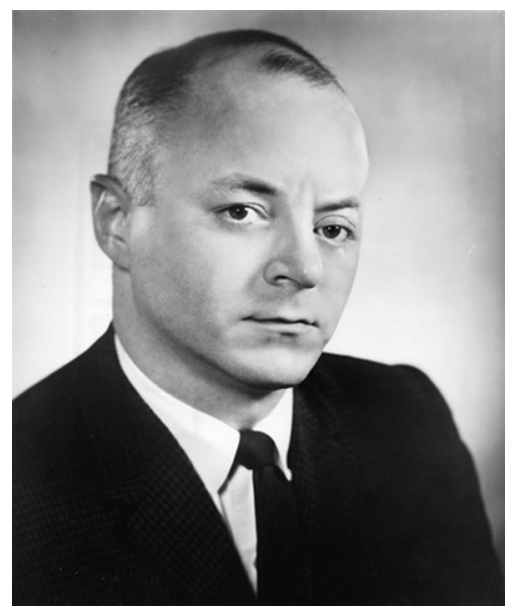

FIG. 3 George E. Block, MD (1926-1994) Former Thomas D. Jones Professor of Surgery, The University of Chicago. Courtesy of The University of Chicago News Office 
(Fig. 4). Bill Blaisdell was an outstanding surgeon, a dedicated educator, and arguably the father of modern trauma care. The UCSF Residency then was pyramidal. Thirty-two interns would start in general surgery, but only eight would become chiefs. In my third year, Blaisdell called me to his office and told me I would be going into the laboratory. I was extremely happy. Entering the lab meant you made the cut and would be a chief resident. But what he said next was very disturbing. He had "arranged" for me to go to Donald Morton's lab at UCLA. I thanked him and said, "But Dr. Blaisdell, I want to be a vascular surgeon. Morton is a surgical oncologist." Blaisdell was not moved. He looked up from his paperwork and just said, "You can do vascular later" and returned to his paperwork. I was really upset. Cheryl was working at UC Berkeley and was even more upset.

We had to leave San Francisco for Los Angeles for a lab I did not want to be in! It was a long unhappy drive. Among the promises I made during that drive was to not move again unless it were for a job for Cheryl. Residents can't believe that's how I started in surgical oncology but, in fact, that is how it happened. In a pyramidal system, when the chief told you what you should do, you did it. Those of you who trained in that system know how bad it was. In Los Angeles, Donald L. Morton, past president of this Society and Chief of Surgical Oncology at UCLA, became my mentor, later my colleague, and then a dear friend (Fig. 5). Don had an extraordinary life. His father was a coalminer in West Virginia. As a teenager, he went to California alone, attended State College, then Berkeley and UCSF. He became an extraordinary leader in our field

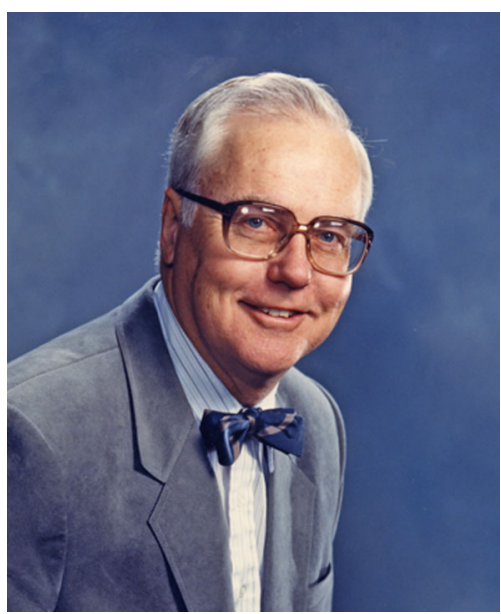

FIG. 4 F. William Blaisdell, MD, former Professor of Surgery, University of California-San Francisco, and former Chief of Surgery, San Francisco General Hospital; Copyright UC Regents/UC Davis Health

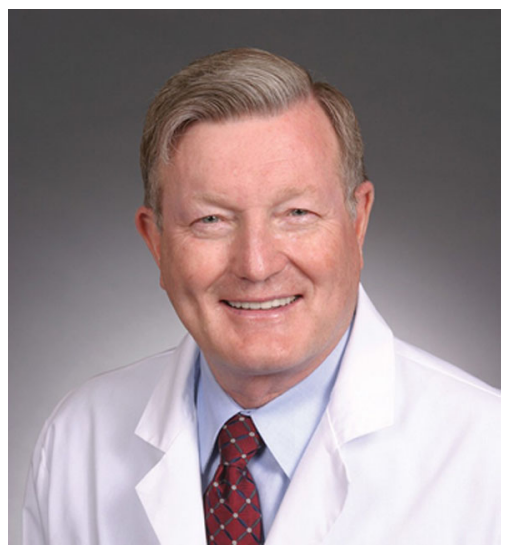

FIG. 5 Donald L. Morton, MD, Former President of the Society of Surgical Oncology. Courtesy of Donald L. Morton, MD

and SSO president. At UCLA, Don ignited my interest in surgical oncology and his laboratory got me interested in research. He supported my career until the day he died.

Don had tremendous, intellect, and vision. He predicted the value of immunotherapy for melanoma decades before it became a reality. Together we left UCLA and founded the John Wayne Cancer Institute. Years later even though he was dying of chemotherapy-induced cardiomyopathy, he supported my leaving John Wayne because he felt it would be best for me. Dr. Morton's impact on the practice of surgical oncology cannot be overestimated. There are many women and men in this audience whose careers and lives were changed for the better by Don Morton.

In 1956 Bernard Fisher was a young surgeon studying liver regeneration and transplantation. He received a call from I.S. Ravdin, his mentor at Penn. According to Dr. Fisher, Ravdin "commanded him" to attend a meeting to discuss clinical trials for breast cancer. Bernie said he had no interest in breast cancer but went because he was "commanded" to go by his former chief, a parallel to Blaisdell in my own career. Out of that meeting came the NSABP and the first prospective randomized surgical trial in breast cancer.

Fast forward three decades. When I began my career at UCLA in general surgical oncology, I experienced the angst of trying to start an academic career. Like Fisher, I had no interest in breast cancer but I went to an NSABP meeting and was inspired by Fisher's leadership and ability to get practicing surgeons to contribute to clinical research. I was intrigued by the concept of randomized clinical trials. While common now, they were unusual when I started my academic career. Thanks to Fisher, I began to contribute to clinical trials and the treatment of breast cancer. Recently I was honored to spend an afternoon with him (Fig. 6). Bernie Fisher just turned 100 years old and is still going to his office. God bless him and give him many more years. 


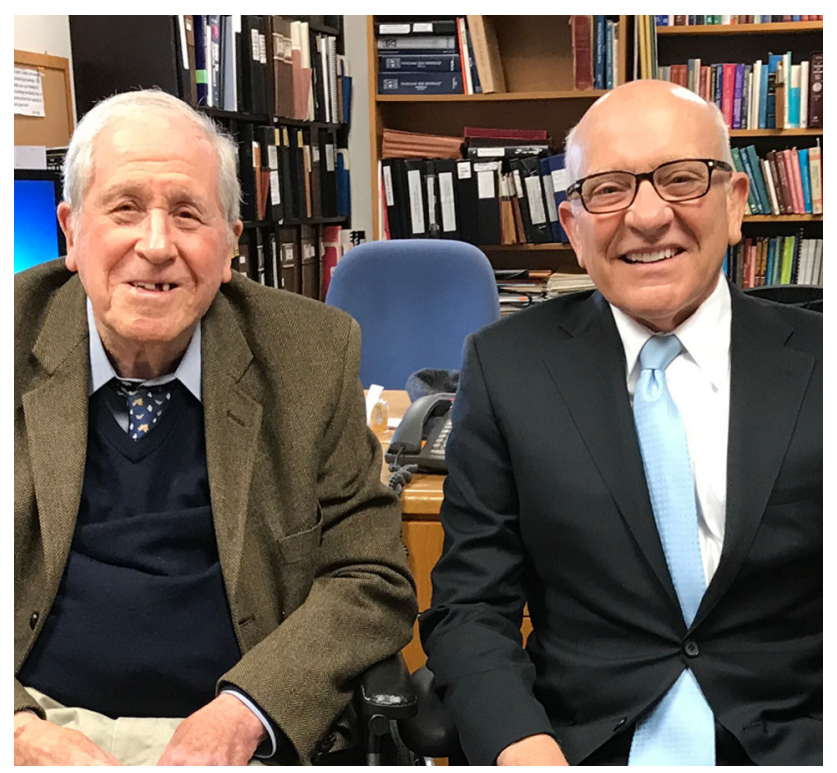

FIG. 6 Bernard Fisher, MD, Past Chairman of NSABP and University of Pittsburgh Distinguished Service Professor of Surgery with Armando E. Giuliano, MD, in Dr. Fisher's office where he still works

Early on, serendipitous events led me down paths quite different from what I had planned. However, the next tale I will tell is less about serendipity and more about holding fast to strategy despite obstacles and stairs to climb. It is through strategic, deliberate work that we can best effect change.

Surgeons are skeptical. We must be. Changing practice and changing the way surgeons think about a disease are some of the most difficult changes to accomplish in our profession.

As you can tell by looking at me, I have been in surgical oncology for a long time. Many practice changes have occurred. Most of them have been initially resisted. Laparoscopic surgery- "no good." Skeptics thought, "You have to be able to feel the tissue." Robots-really? Lumpectomy was at first considered inadequate. Multifocality. Mastectomy was considered essential. It took decades to accept breast conservation. "Sentinel node biopsy will leave residual disease, leading to unnecessary deaths." I know a lot about that one. My research in sentinel node biopsy was often a difficult and, at times, a painful experience.

In 1991, Don Morton was investigating sentinel node biopsy for melanoma. I tried the same exact technique for breast cancer. I knew identification of a tumor-free axilla without an axillary dissection could greatly alter management. But I just could not identify a sentinel node. After about 10 or 15 attempts, I became the first to conclude sentinel node biopsy would never work for breast cancer.
When I told Don it wouldn't work, he said, "Re-search, re-search means search again"! So I kept trying. A complex general surgical oncology fellow, Dan Kirgan, who is likely in this audience and is now Professor of Surgery at the University of Nevada, came onto my service. In a bar at the annual meeting of the American College of Surgeons, on the back of a napkin, Dan and I strategized and sketched a plan to identify a sentinel node in breast cancer. We altered several variables and eventually created an algorithm that worked. When it worked, I applied for a grant and was soundly rejected: “... the search for a sentinel node in breast cancer might turn out to be a magnificent surgical 'tour de force' but without adding very much to the management of breast cancer." Research. Search again. Try again. Obstacles are an inherent part of the process.

Once I began speaking and publishing, there was tremendous skepticism. There were questions about the accuracy of the technique and the veracity of the data. There was animosity toward the very idea of omitting axillary dissection from breast cancer treatment and towards me personally for proposing it. Many in this Society felt the presented data was not accurate. SSO President Bill Wood visited me to observe some cases (Fig. 7). It was a good day. Things went well. Bill became a great supporter and dear friend (Figs. 8, 9).

Before they would accept the staging accuracy of the procedure, many surgeons then demanded a randomized trial for the sentinel node-negative woman. When past president Sam Wells asked for a study of sentinel node biopsy for ACOSOG (Fig. 10), I was very much against a

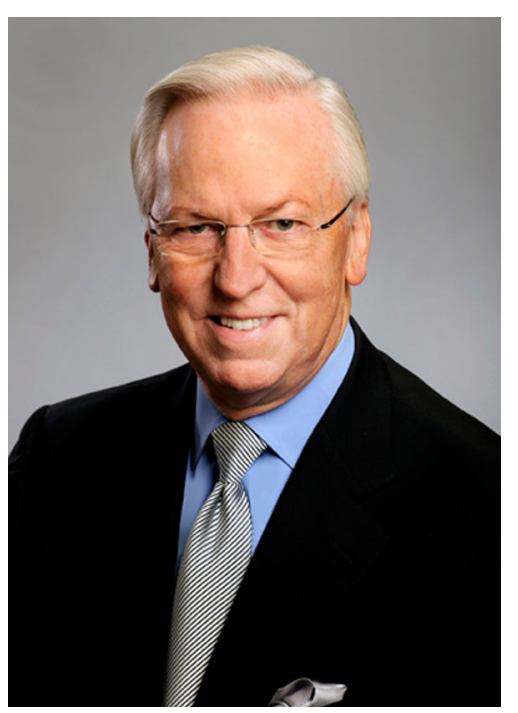

FIG. 7 William C. Wood, MD, Former President of the Society of Surgical Oncology; former Chairman of Department of Surgery, Emory University School of Medicine. Courtesy of Emory University School of Medicine 
FIG. 8 Letter to Bill Wood re new procedure

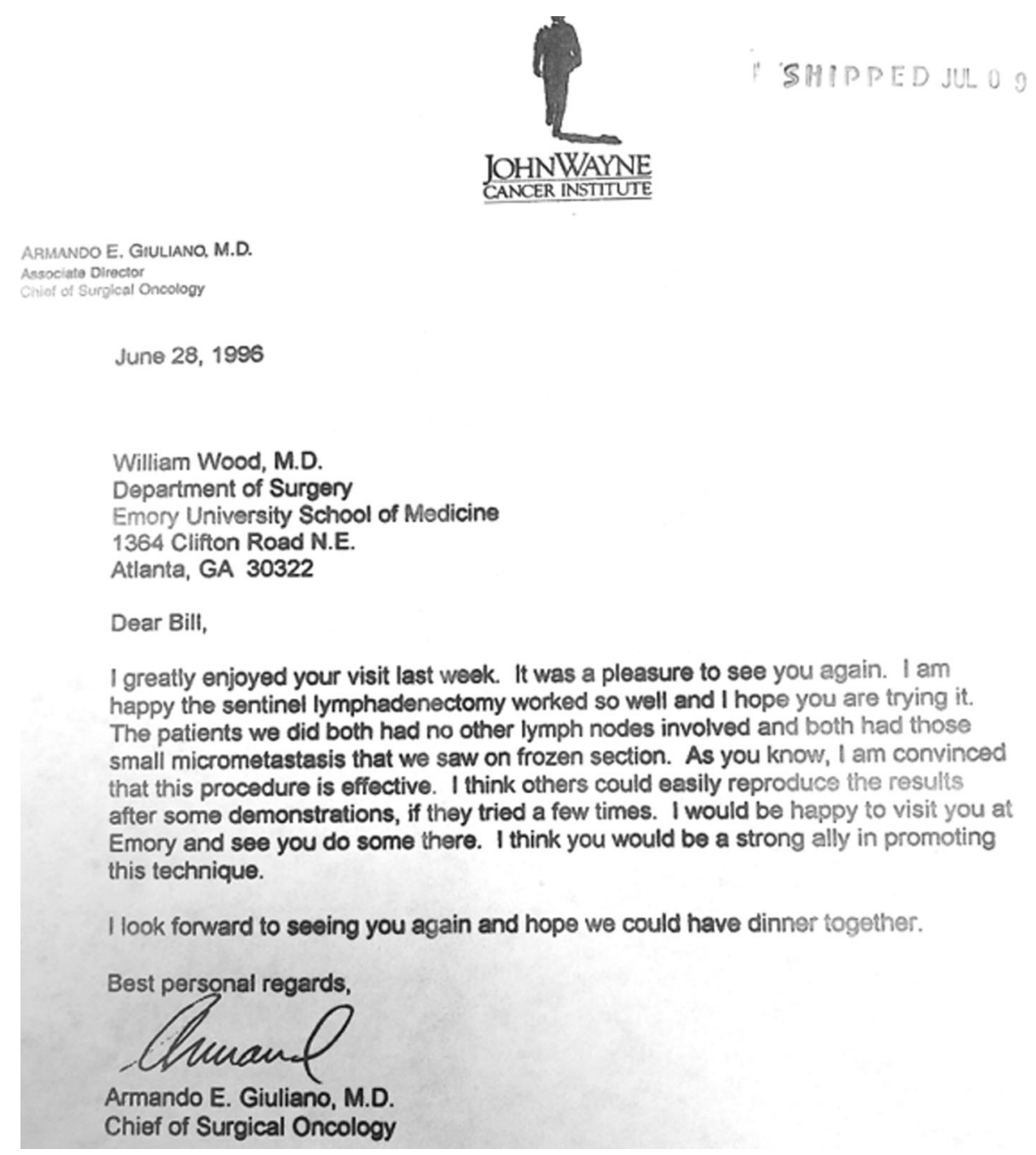

node-negative randomized study; fortunately others were too. Why randomize node-negative women to an axillary dissection?

Charles Cox and Doug Reintgen, who ran a great course on the technique at Moffitt in Tampa, were also against a randomized study. We strategized and convinced Sam Wells to let us do ACOSOG Z0010, a prospective study evaluating the relevance of micrometastases. Even though many believed axillary dissection was necessary for patients with sentinel node micrometastases, the Z0010 study showed micrometastases are of no clinical significance with modern breast cancer management.

The real struggle came with Z0011, a randomized trial of axillary node dissection in women with a positive sentinel node. I naively thought this would be an easy study to do. It was merely a high-tech repeat of NSABP B-04 done in the 1970s when clinically node-negative women were randomized to axillary radiation, axillary dissection, or no axillary treatment. There was no adjuvant systemic therapy. I felt confident that surgeons would support Z0011 and that ACOSOG would be successful in involving more surgeons in clinical trials. I never anticipated the animosity towards the study nor toward me.

Some surgeons felt that there would be en cuirasse axillary metastases necessitating fore-quarter amputations. Others were reasonably opposed to leaving undissected cancer in the axilla. Many refused to participate in Z0011. Some IRB's would not even approve the study and deemed it "unethical." I have a collection of letters and emails describing my overall poor judgment and lack of ethics. At times I even questioned it myself. We could not have done this trial if Sam Wells and I had not been convinced of the clinical science and if it did not have the support of many friends and colleagues. Sam Wells was totally committed to surgical science. Former fellows were arm-twisted into participation and randomized many of the patients.

Even though 10-year results have shown no benefit of axillary dissection, many surgeons still view the study with skepticism and will not abandon ALND. No surprise. It 


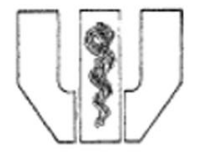

\section{EMORY UNIVERSITY SCHOOL OF MEDICINE}

DEPARTMENT OF SURGERY

Emory University Hospital, 1364 Clifton Road, N.E., Allanta, GA 30322

WILLIAMC WOOD M.D

Joseph Brown whitehead Proressor and Chairman

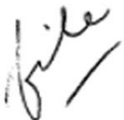

(404) $727 \cdot 5800$

July 2, 1996

Dr. Armando E. Giuliano

John Wayne Cancer Institute

2200 Santa Monica Boulevard \#105

Santa Monica, CA 90404

Dear Armando:

Many, many thanks for the generous gift of your time in showing me the sentinel node technique for the axilla as you have developed it. Much of what you showed me I could not have appreciated from a written description. It was delightful to spend the time with you.

I was also very pleased to see the happy situation that you and Don have at the John Wayne Cancer Center.

All best wishes. I look forward to seeing you in the near future.

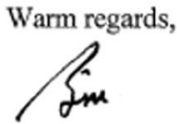

WCW/ab

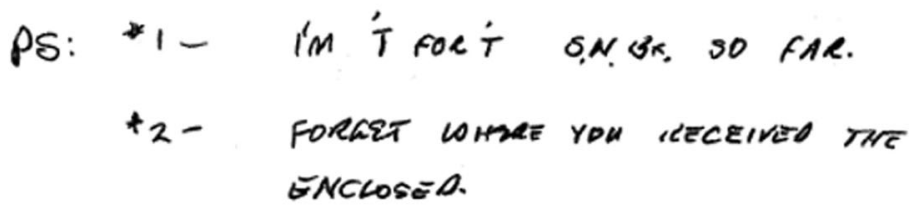

8

THE ROBERT W. WOODRUFF HEALTH SCIENCES CENTER

FIG. 9 Letter from Bill Wood re new procedure

took decades to accept breast conservation. I am grateful to all the surgeons who participated in Z0011 and to the 891 women brave enough to accept randomization.
Other changes in life are even more difficult to accept than choices in one's career or results of clinical trials. My wife Cheryl's illness has been a painful and difficult 


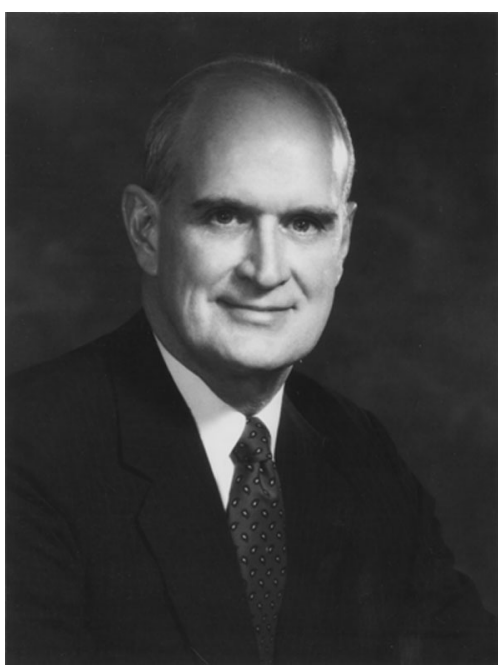

FIG. 10 Samuel A. Wells, Jr., MD, Founder and Former Chairman of the American College of Surgeons Oncology Group. Courtesy of Washington University Department of Surgery

change for the entire family but a change to which we must adapt. We all must try to accept those changes we cannot control. At times you have to adapt just to go on.

The SSO is changing. It too must adapt. The profession has changed. Our culture has changed. While many events in my career were serendipitous, the proposed SSO changes are strategic. I would like to present the Strategic Plan of the Society of Surgical Oncology - a plan thoughtfully, purposefully, and deliberately designed to enable the SSO to remain relevant and to fulfill its mission.

A reminder: what is our mission? Our mission is to advance "the science, education and practice of cancer surgery worldwide." That is why this organization exists. That is why we are members. That is the goal of the Society and the new strategic plan. But change is hard. Many members of the SSO will likely object and resist the changes proposed. However, progress only occurs with change.

Change is not new for our Society. We have adapted in the past. As you know, the Society began as a Memorial Hospital Alumni Society and shortly thereafter became the James Ewing Society, named after the director of Memorial Hospital. Decades later the Ewing Society's leaders realized that to have greater impact and to more profoundly improve cancer care, the Society needed to grow and be accessible to surgeons throughout the country.

This realization resulted in the Ewing Society's name change to the Society of Surgical Oncology. This simple change was greatly resisted. According to Blake Cady's 1989 presidential address, discussion of the name change was "emotional with angst and turmoil." I can only imagine. But that change was necessary to position the Society to support the profession with a greater sense of purpose and scope. The Society grew as designed. But growth came primarily from academia, and by the late 1980's the SSO had become almost entirely an academic organization even requiring publications in oncology to be a member. The Society stagnated, forcing it to reflect on its role in the profession. How could the SSO advance surgical oncology? In his presidential address of 1990, Benjamin Rush stated, "If the Society intends to work successfully, it must represent most surgical oncologists."

1991 to '94 were years of major strategic change including a reorganization of the annual symposium, the administration, and membership requirements. Charles Balch - who has done so much for the SSO and Don Morton, expanded the Society with a recruitment drive and elimination of publication requirements for membership. More cancer surgeons participated and the SSO grew.

Other dramatic changes were more recent but equally strategic. In 2011, we adopted our current mission statement. In 2012, we went to self-management, a risky but important and successful change. The SSO truly became a modern, full-service organization. We expanded educational offerings and began international partnerships.

To ensure our viability and relevance in the future, in 2018 we initiated our new, current strategic plan. A great deal of work was performed to develop this plan. We had a leadership retreat. Collected data. Consultants were hired, data reviewed, task forces appointed, and a plan was proposed, supported, and approved by leadership. This plan, like previous strategic plans, considers the needs and culture of the members, changes in the profession, and the best path forward.

Our new strategic plan emphasizes inclusion, transparency, and engagement. Inclusion is a powerful theme that affected change at several points in the Society's history from changing the name to omitting publication requirements, changing committee structure, and leadership nominating procedures.

Why must we change yet again? Most of us really like the SSO. But there are many reasons to change. We continue to lose members to specialty societies. Our surveys and task force reports repeatedly show that many members perceive us as a purely academic society, lacking sufficient inclusivity and transparency, two concepts essential for our growth and success. In addition, our meeting has not changed, despite changes in educational needs of surgical oncologists.

We plan to increase meeting attendance, increase membership, impact the community, and position ourselves more solidly on the world stage. Here's one change I guarantee everyone will like. The Program Committee has shortened the time for the presidential address-a first step to make the annual meeting more interesting. 
The strategic plan, which will transform the Society, has six goals:

- Reimagine the Annual Cancer Symposium

- Grow a membership that is more inclusive of all cancer surgeons

- Expand our global outreach

- Further support career-long education, recertification and quality patient care

- Strengthen our brand image

- Maintain Organizational vitality.

All our goals go hand in hand. Each goal achieved increases the value and scope of the Society. And all goals work together to improve and enhance our member's experience.

To enhance the annual meeting, a Reimagination Task Force was formed of 20 members from various career stages and practice settings. The Task Force evaluated years of data to recommend a more contemporary and engaging meeting. Some of their 28 recommendations are already in effect including enhanced networking opportunities, more interactive technology, and more presentations. There is even a Human Library where members can meet with a representative of a Disease Site Work Groups to discuss a challenging case. This is just the beginning of what will become an even more engaging symposium.

Next year our traditional exhibit hall will be replaced by the SSO HUB. Our hallway conversations will take place in a comfortable community environment. The HUB will be organized in disease-specific zones with case presentations, discussions, debates, and industry spotlights. An informal meeting place is often good for networking and exchanging creative ideas. Remember, in an informal atmosphere on the back of a napkin, Dan Kirgan and I planned the study that led to sentinel node biopsy success in breast cancer.

All members-young and old, academic and non-academic-will have an opportunity to feel included in the SSO. To that end, I have appointed a very diverse group of members to our committees. In the past, like other surgical societies, we have not been a model of diversity. Thanks to the Nominating Committee's comprehensive review of our membership, we have several more women in place to become Society president. But we have more progress to make.

The issue of opportunity bias is a topic taken very seriously. I have formed a Diversity and Inclusion Advisory Board with a diverse membership to be certain that the Society provides equal leadership and engagement opportunities to all members. This Advisory Board, chaired by past president Monica Morrow, met last month and will advise the Executive Council to ensure we capitalize on the strengths of all our members.

To grow and achieve our mission, membership must be representative of cancer surgeons from all practice settings and all locations. In the U.S. about $80 \%$ of cancer operations are performed in the community. For the SSO to significantly improve cancer care, we must support the needs of community cancer surgeons. We plan to attract more community surgeon members while we continue to highly value and capitalize on the expertise and leadership of our academic members. Our strategic plan contains a membership drive and community outreach. I believe President Benjamin Rush in 1990 was correct. We must represent all surgical oncologists.

Since our mission is worldwide, we must also engage surgeons abroad, especially in developing countries. Our Strategic Plan has specific ideas for increasing global outreach. The SSO will improve collaborations with our eight International Partner Societies and increase international membership to engage surgical oncologists abroad.

To provide a voice for the cancer surgeon on the global stage of medicine, the SSO convened the Global Forum of Cancer Surgeons. Under our leadership, this group of 12 international societies will meet again here. The SSO is a member of the Union for International Cancer Control. We collaborate with the European Society of Surgical Oncology and are creating a global training curriculum to impart surgical oncology training worldwide. Over 300 international surgical oncologists are here at this meeting.

The SSO is known for premier educational programs developed by our academic leaders. Our fourth strategic goal is to further strengthen education. Our Education Council is focused on supporting career-long education and quality care. By the end of this year, the Council will have produced nearly 50 new educational programs. These will be found on our new learning management system, ExpertED@SSO.

To be effective, we must maintain the organization's infrastructure. The operational elements and needs of the Society are important components of the plan. CEO Eileen Widmer works with the Executive Council and the Finance Committee to ensure operations and infrastructure function well and within budget.

A final and important goal is the development of our brand. What is the SSO? What does it mean to be a member? What value does membership provide? A strong brand identity can answer these questions. I had the privilege of unveiling our new brand image (Fig. 11). The SSO's new brand emphasizes our leadership strengths and projects our open, inclusive, and forward-thinking culture. The brand also illustrates our global community and our 


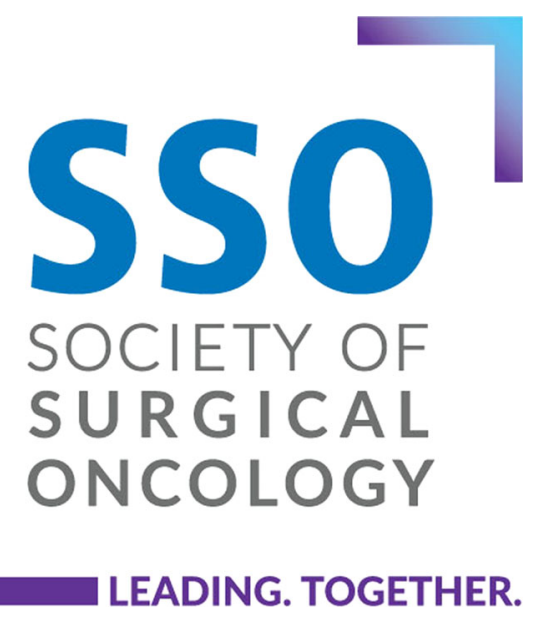

FIG. 11 Society of Surgical Oncology new logo

collective desire for new programs, new solutions, and new advancements. We use the words "Leading. Together." to reflect our position as THE organization of likeminded members working together and leading the profession.
I believe this is an exciting time to be a member of the SSO. Surgical oncology is evolving. Our membership demographics are changing. Just look around. The SSO must strategically prepare for tomorrow. Those of you who have been members for many years have seen the Society grow and change into an efficient, self-managed organization. Your loyalty and leadership have served us and the profession well. Please continue to support the SSO and this strategic plan. Help guide us into the future. But this plan will have the most impact and meaning for our young members. We need your energy, passion, and commitment to carry the organization forward.

Change can be hard. It can be resisted, but it is inevitable. A quote often mis-credited to Darwin may say it best: The species that survives is not necessarily the strongest but the most adaptable.

Our strategic path will no doubt be influenced by chance and serendipity, but it will create new opportunities with more transparency, inclusivity, and great progress. Our Society has a vision for the future. Leading together we will achieve our mission: to improve cancer care worldwide. Leading. Together. We can create the future of surgical oncology. 